\title{
Indemnity in the spotlight
}

\author{
Peter Ward
}

Managing Director, BDA

The BDJ Upfront section includes editorials, letters, news, book reviews and interviews. Please direct your correspondence to the News Editor,

Adrian O'Dowd at BDJNews@nature.com. Press releases or articles may be edited, and should include a colour photograph if possible.

$\mathrm{P}$ rofessional indemnity is under the spotlight. A consultation announced by the UK government in December 2018 explores whether it should be subject to tighter regulation consistent with that of the wider insurance industry. The consultation is likely to have significant consequences to the current indemnifiers and their members. We would urge dentists to comment before the deadline on 28 February $2019 .{ }^{1}$

Over $90 \%$ of dental professional indemnity in the UK is currently provided by three mutual discretionary organisations (MDOs): the Medical Protection Society (via Dental Protection), the Medical Defence Union (via Dental Defence Union) and the Medical and Dental Defence Union of Scotland. These are not insurance companies and are not subject to the regulations that control insurance companies. The consultation posits that the matters of their business are so important that they should be subject to the same regulation and protections that are in place to protect the consumers of true insurance companies.

The big difference between MDOs and insurance companies is the relationship between the company and the client. True insurance companies provide the client with a legal contract. The conditions of insurance are confirmed at the outset. MDOs have no such undertaking. Their clients have a right to ask the MDO to exercise its discretion and settle any claims on their behalf. The MDO retains the discretion to either accede to that request or not. This discretion brings about uncertainty whether that payment will definitely be made. If the discretion is declined, both client-dentist and injured-party-patient are disadvantaged. The premise of the consultation is that subjecting MDOs to the same set of regulations would remove uncertainty.

As is often the case, something that seems obvious and desirable has other consequences. In this case, the consequences are financial.
Current rules relating to insurance companies demand that they calculate precisely their risk exposure and carry assets to cover them plus a wide safety margin. The details are laid down by law to minimise the risk of there being insufficient funds to meet all claims.

Currently, the levels of cover maintained by the MDOs are much less strictly controlled in almost every respect. The presence of the discretion (whether to pay or not) gives them latitude in deciding how much is enough. In all cases the MDOs' assessment of 'how much is enough' falls well short of that required within a regulated environment. Because there is no robust external scrutiny, nobody outside the organisations can be certain about whether the assets are sufficient for all future eventualities. If made to comply with new rules, they and appropriately funded if we are to avoid massive disruption within dentistry.

Discretionary indemnity cover has served society well for over a hundred years, but if the time has come to move to another model, the move must be considered and managed.

It is likely that these changes will raise the cost of conventional indemnity arrangements. In such circumstances dentists may look for cheaper options and this has the potential to produce gaps in cover or unprotected potential losses. One example of this is a type of insurance contract called 'claims made. The potential for gaps in this type of cover may result in it being no more 'certain' than discretionary indemnity. In fact the only certainty is the absence of cover in a range of common situations.

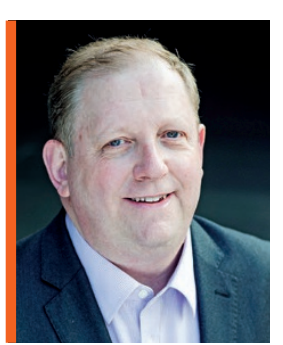

\section{'It is not just or equitable for dentists alone to be footing} the bill'

would need to significantly strengthen their reserve accounts to make up the shortfall. Having made up the shortfall, they would then need to maintain substantially greater capital reserves to satisfy the rules.

So, where should the additional resources come from? Within dentistry we already have experience of the profession being expected to fund $100 \%$ of the costs of regulation by the GDC, and by CQC and equivalent organisations, when the regulatory structure is designed to benefit the public, not the profession. If we are to constructively engage with what is an important discussion, it must be in the context that it is not just or equitable for dentists alone to be footing the bill. Any transition must also be incremental
Throwing light on all the technical complexity of professional indemnity has been long overdue. For the last six months the BDA has invested heavily in assessing the experiences, concerns and needs of dentists with regard to their professional indemnity.

Dentists must not assume that what has worked for them in the past will properly serve them in the future. The BDA's role is to put its members into a position where they can make informed and considered decisions, and professional indemnity is one of those decisions that can make or break a professional career. DOI: $10.1038 /$ sj.bdj.2019.12

1. Department of Health and Social Care. Appropriate clinical negligence cover. Available at https://consultations. dh.gov.uk/resolution-patient-experience-and-maternity/ indemnity-regulation (accessed December 2018). 